\title{
O PROCESSO DE MUDANÇA E ADAPTAÇÃO ESTRATÉGICA COM BASE NO MODELO DO PROCESSO EMPREENDEDOR DE JEFFREY TIMMONS
}

William Rafael Cararo ${ }^{1}$

Alessandro Becker ${ }^{1}$

Jorge Oneide Sausen ${ }^{2}$

${ }^{1}$ Business school / IMED / Faculdade Meridional (IMED)

${ }^{2}$ Universidade Regional do Noroeste do Estado do Rio Grande do Sul 


\section{O PROCESSO DE MUDANÇA E ADAPTAÇÃO ESTRATÉGICA COM BASE NO MODELO DO PROCESSO EMPREENDEDOR DE JEFFREY TIMMONS}

Resumo: As mudanças fazem parte do cotidiano das empresas independente do nicho de mercado. Essas fazem com que as empresas estejam em processo contínuo de modificação e adaptação para se manter em um mercado competitivo. Deste modo o estudo analisa o processo de adaptação e mudança estratégica da organização Sivet, situado no Rio Grande do Sul e atuante no cenário do agropecuário. A análise dos acontecimentos foi através da "direct research", de forma qualitativa, descritiva de forma longitudinal. Realizou-se assim uma análise e interpretação interna e externa dos fatores que contribuíram para o processo de mudança da organização, mais especificamente verificando os períodos por meio do modelo adaptado do Processo Empreendedor de Jeffrey Timmons. Revelou-se três períodos de escolha, sendo eles, inicialmente o determinismo do ambiente (Período I), cruzando pelo posicionamento e inovação (Período II) passado pela organização e pôr fim a expansão e crescimento (Período III).

Palavras-chave: Mudança organizacional. Empreendedorismo. Determinismo Ambiental.

\section{Introdução}

Mudança e estratégia fazem parte do cotidiano das organizações sejam elas de qualquer ramo. Uma das certezas que a humanidade tem é de que mudanças acontecem, sejam elas na vida pessoal sejam no mundo dos negócios. Entrando na seara dos negócios, uma evidência é que poucas empresas que começaram a década de 80 como líderes em seu segmento de atuação conseguiram finalizar a década com sua posição de liderança intacta e inalterada (HAMEL; PRAHALAD, 1995).

A mudança causa interrupção do sucesso de alguns negócios que por outro lado são transformados em oportunidades por outras empresas. Peter Drucker (1995) contribuiu no sentido de afirmar que nos defrontamos com uma época de descontinuidade da economia e da tecnologia em que as mudanças ocorrem nas estruturas industriais bem como no conhecimento necessário para a gestão das empresas.

A estratégia assim como a mudança tem um papel relevante no mundo dos negócios. Ela requer uma série de decisões que definirão o rumo da empresa em um mercado competitivo. Mintzberg (2000) comenta que a formação de estratégia é um espaço complexo. Hamel e Prahalad (1995) complementam que a estratégia tem tanto a ver com a competição pela futura estrutura do setor quanto com a competição dentro da atual estrutura do setor.

Contribuindo com os estudos de estratégia e mudança é apresentado o processo empreendedor de Timmons, sendo visualizado tendo como base a lente estratégica no lugar de sustentabilidade. O estudo desenvolvido buscou compreender o processo de mudança
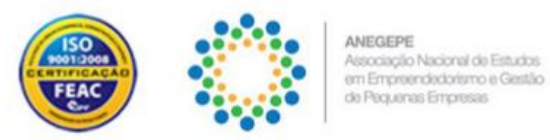

Realizadores:
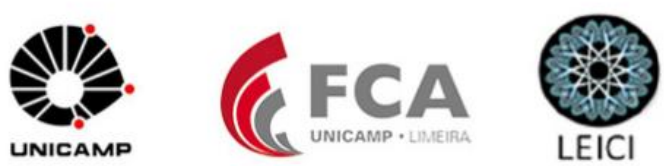
estratégica por meio de um estudo caso único de um empreendimento do setor agropecuário no Norte do Estado do Rio Grande do Sul. A empresa analisada comercializa produtos de uso veterinário. O período para análise das mudanças e adaptações estratégicas foi do ano de 2006 ao ano de 2016.

O trabalho desenvolvido é composto por mais quatro seções, além desta introdução, a seção seguinte relata o referencial teórico, mantendo o foco em mudança e adaptação estratégica e ainda trazendo como inovação o modelo adaptado do processo empreendedor de Timmons; em seguida o trabalho apresenta o método utilizado, em sequência os resultados e análise dos mesmos; por fim a consolidação de todo o estudo, ou seja, as considerações finais.

\section{Referencial Teórico}

\subsection{Mudança e Adaptação Estratégica}

O processo de mudança das organizações ocorre de forma contínua independente do segmento de atuação da organização, e para sua sobrevivência e desenvolvimento a mudança é necessária devido as novas tecnologias, concorrentes e a evolução do mercado competitivo. Para isso as organizações necessitam estarem preparadas, deste modo estudiosos no campo de estratégia classificam em dois aspectos o determinismo do ambiente, que ocorre quando o ambiente tem grande fator para a estratégia da empresa e o voluntarismo, que nada mais é quando a empresa tem força estratégica para manipular o ambiente que está inserido (ROSSETO, 1998).

A estratégia também é considerada como a forma invisível que as organizações têm de atuar no mercado, sendo elas tanto como forma de se adaptar, reestruturar e gerenciar-se perante as mudanças. Sendo utilizada no momento e de forma adequada (CERETA; SAUSEN, 2010). Essa adaptação estratégica é a forma sob a qual as organizações se mantêm competitivas, em função de novas exigências que o ambiente ou concorrentes podem proporcionar, podendo agir tanto de forma determinista quanto voluntarista.

Para análise da organização deve se manter como foco inicial a formulação do conteúdo, envolvendo tantos processos internos e culturais que envolvem a organização. Essas características com políticas da organizacionais, o processo, exercem influência sobre as ações e interações que a organização adota, ou seja, resulta no contexto organizacional (PETTIGREW, 1987; LAZARETTI et al., 2012). A mudança ocorre em base do conteúdo, contexto e os processos de mudança e adaptação estratégicas que ocorrem na organização, desta forma as análises devem suceder em base do conteúdo, processo e contexto que a organização esta inserida (PETTIGREW, 1987).

\subsection{Empreendedorismo: A Formulação da Estratégia como um Processo Visionário}

A Escola Empreendedora, abordada por Henry Mintzberg, Bruce Ahlstrand e Joseph Lampel (2010), apresenta o processo de formulação da estratégia à medida que este se desdobra. Sua essência está na formulação da estratégia com foco exclusivo na visão do líder, é considerado uma obra do líder. Os defensores desta escola visualizam a liderança personalizada, baseada na visão estratégica, como a chave para o sucesso organizacional. É defendida por esta
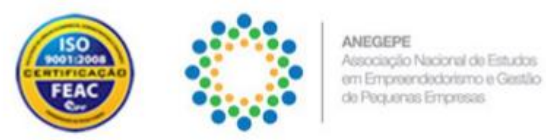

Realizadores:
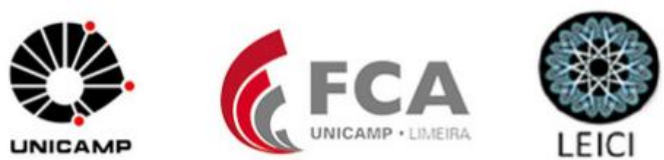
escola que os empreendedores são impulsionados por poderosas necessidades de realização e independência.

As premissas dessa escola são de que a estratégia existe na mente do líder como perspectiva, especificamente um senso de direção de longo prazo, uma visão do futuro da organização. O processo de formulação da estratégia é, na melhor das hipóteses, semiconsciente, enraizado na experiência e intuição do líder, que ele concebe a estratégia ou adote de outros e a interiorize em seu próprio comportamento. (MINTZBERG, AHLSTRAND, LAMPEL, 2010).

Na perspectiva de Dornelas, Spinnellie e Adams (2014), os empreendedores criam ou identificam e seguem oportunidades organizando os diversos recursos necessários para desenvolver novos mercados e enfrentar a concorrência. Eles estão convencidos de que a criação e a liberação de energia humana por meio do empreendedorismo é a maior força transformadora que existe hoje no planeta.

Para Schumpeter (2004) o sucesso do empreendedor depende da intuição, da capacidade de ver as coisas de uma maneira que posteriormente possa ser considerada verdadeira, mesmo que no momento isso não possa ser comprovado.

\subsection{O Modelo de Jeffrey Timmons}

Para Lazzaretti et al. (2012) estudos realizados sobre a escolha e adaptação estratégica tentam a mostrar como as organizações atuam em diferentes ambientes buscando melhorar sua competitividade perante o mercado. Deste modo, o estudo se baseia no modelo proposto por Timmons para analisar o processo da estratégia empreendedora, sendo ele composto por oportunidade, recurso e equipe.

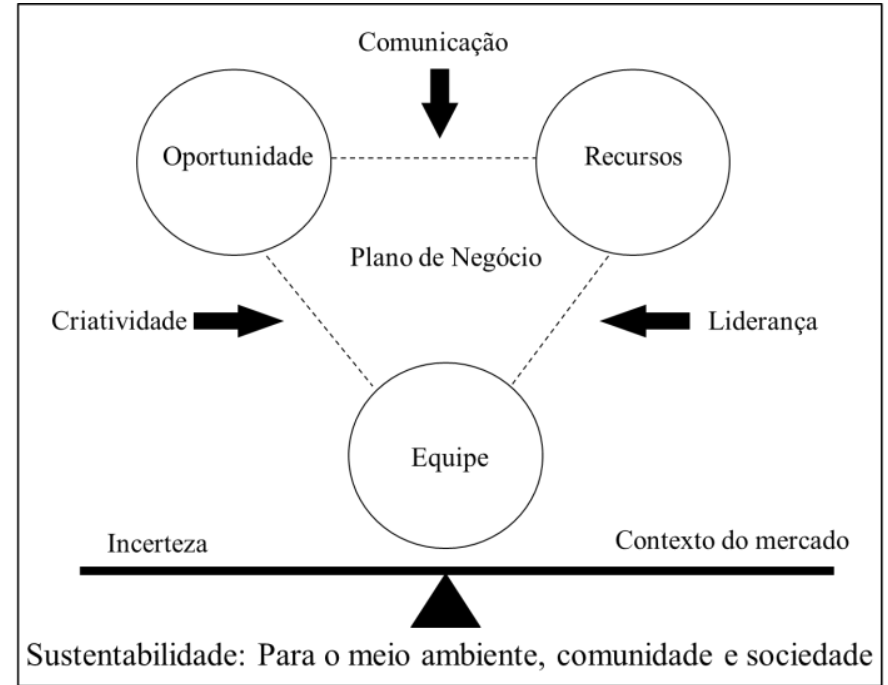

Figura 1: Processo empreendedor - Modelo de Timmons.

Fonte: Adaptado de Jefrey Timmons apud Dornellas et al. (2011). 
Todos estes componentes afetam o processo do empreendedor, podendo ser influenciado e também alterados durante o processo e assim determina as mudanças para aumentar as chances de a empresa ser bem-sucedida.

Em termos de oportunidade apresenta-se de forma geral a profundidade dos recursos e da equipe, mas principalmente o foco no mercado e na visualização de novos produtos ou serviços e com isso buscando informações e aprimorando-se (DORNELAS et al., 2011). Para este autor é um erro pensar em recursos somente como o dinheiro, mas deve sim com a inteligência de utilizar aquilo que tem da melhor forma e assim enfrentar as dificuldades. $\mathrm{O}$ ingrediente chave como equipe empreendedora afeta de forma significativa a atividade da organização, devendo trabalhar de forma unida e o líder empreendedor precisa apoiar em momentos de fracasso e incentivar nos momentos de dificuldades.

Recursos envolvem pessoas, dinheiro, ativos e o plano de negócios na visão de Dornelas, Spinelli e Adams (2014). O êxito está em perceber a necessidade, propriedade e administração dos mesmos na busca de oportunidades diferentemente de outros empreendedores. Para Stevenson (1984) o empreendedor precisa controlar os recursos que precisa, ao invés de possuilos, e em algumas ocasiões não possuir o recurso pode proporcionar algumas vantagens, sendo assim, o autor considera as decisões sobre recursos extremamente complexas.

$\mathrm{O}$ acesso a recursos financeiros e não financeiros vem sendo facilitado pelo uso da internet, e os empreendedores exitosos necessitam adotar estratégias criativas de autossuficiência para organizar e minimizar recursos (STEVENSON, 1994; DORNELAS, SPINELLI, ADAMS, 2014).

No modelo original de Timmons consta a sustentabilidade como base da organização empreendedora, porém, nesse trabalho foi adaptado a sustentabilidade pela influência da organização no meio que está inserida, ou seja, interpretando ela como processo de mudança estratégica. Apresentando ela assim como base, a incerteza do ambiente, representa o determinismo do ambiente, e na outra extremidade a empresa atuando com escolha estratégica, representando um maior voluntarismo como apresentado na Figura 2.

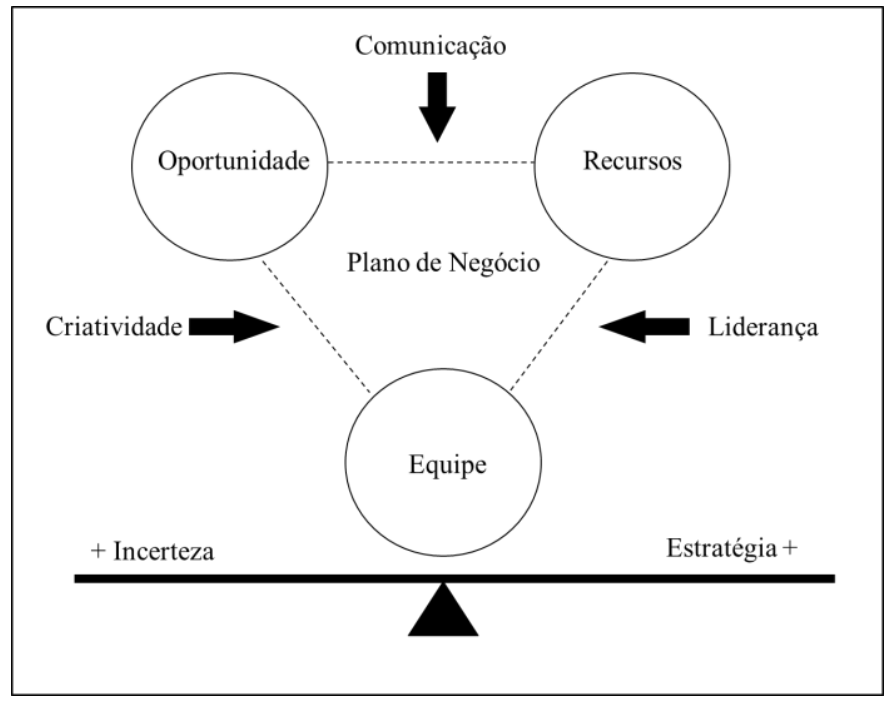

Figura 2: Modelo do Processo do empreendedor - Interpretado para mudança estratégica. Fonte: Adaptado de Jefrey Timmons apud Dornellas et al. (2011). 


\section{Método}

A seguinte pesquisa é um estudo de caso simples (YIN, 2001), de cunho qualitativo e descritivo. Foi realizada a pesquisa sobre mudança organizacional no formato histórico, observando desta forma o contexto, o conteúdo e o processo, modelo proposto por Pettigrew (1987). Se referindo a dimensão longitudinal do estudo, desde o início da empresa, 2006 a 2016, a análise da organização foi realizada de forma interpretativa. Os períodos analisados foram delimitados devido a acessibilidade aos dados empíricos fornecidos pelo empreendedor e outros dois colaboradores foram escolhidos devido a relevância dos fatos ocorridos.

Foi utilizada para a coleta de dados um roteiro de entrevista semiestruturado, onde foi realizada a entrevista na própria empresa com duração de aproximadamente 2 horas no mês de julho de 2016. Em que foram relatados os eventos ocorridos no decorrer do tempo de vida da organização, e assim identificou-se 3 períodos significativos de mudanças da organização descritos no Quadro 1.

Para os procedimentos de coleta e análise dos dados, foi adotado a técnica da direct research, tendo como característica marcante, direta e de simples investigação. O pesquisador assemelha-se a um detetive na busca de informações, novas conclusões e possibilidades, também chamado de saltos criativos onde o pesquisador estabelece as decisões (MINTZBERG, 1979). Na coleta foi possível identificar 4 períodos de mudança. O primeiro período nomeado como Início da empresa, o segundo como Desafios de mercado e o último período identificado como Empresa Planejada. A leitura dos dados descritos, são relativas as situações vividas e as decisões estratégicas tomadas pela organização, de cunho longitudinal, evidenciando assim os processos de mudança da organização (MINTZBERG, 1978).

O caso a estudado é uma organização empreendedora situada no norte do Estado do Rio Grande do Sul, que atua no setor agropecuário, fornecendo e distribuindo, tanto produtos próprios quanto de terceiros, para lojas varejistas e produtores rurais. A organização iniciou suas atividades no início de 2006 com 2 colaboradores, o empreendedor e sua esposa. Hoje conta com 13 colaboradores, internos e externos. Atinge o faturamento de uma pequena empresa (R \$ 16 milhões por ano). Foi escolhida esta organização por ir ao encontro do objetivo deste trabalho de analisar as mudanças estratégicas ocorridas no desenvolvimento da empresa e por ser relevante no segmento em que atua. Seu produto, carro chefe, impacta diretamente na cadeia do leite, representando no sul do país 35,6\% da fabricação nacional (IBGE, 2016), e um fator importante também é a forte representação no interior do estado. Desde seu início a empresa obteve grande crescimento, sendo praticamente $100 \%$ a cada 3,5 anos de operação.

Os períodos estratégicos foram validados com o empreendedor e seus colaboradores, para uma maior confiabilidade da pesquisa e para uma análise mais assertiva, evitando desta forma, apenas a interpretação dos pesquisadores.

\section{Resultados e análise}

Inicialmente é feita uma caracterização da empresa e suas atividades. A mesma foi fundada em meados de 2006 devido a uma oportunidade percebida pelo empreendedor, pois atuava como representante comercial de produtos agropecuários, quando identificou a
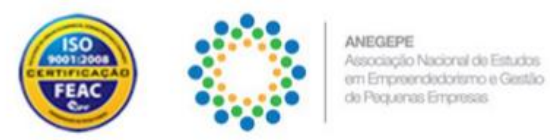

Realizadores:
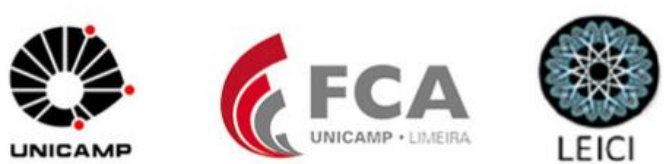
possibilidade de se tornar distribuidor de duas empresas. Foi nesse momento que se iniciou as primeiras atividades desse novo negócio. A empresa está localizada em Erechim no interior do Rio Grande do Sul. Seu início foi com base familiar e apenas dois colaboradores, o empreendedor e sua esposa. Atualmente distribui em todo o Rio Grande do Sul tendo expandido para a algumas regiões de Santa Catarina e Paraná. Atua no setor agropecuário com produtos de fornecedores e também com linha própria. Atualmente seu carro chefe é um produto desenvolvido pela própria empresa onde foi percebida uma necessidade e a mesma impactou fortemente no período estratégico II.

Atualmente a organização possui o seguinte quadro funcional: proprietário que atua como diretor geral, diretor de vendas, diretor financeiro, diretor logístico e 7 colaboradores externos atuando como representantes comerciais e operadores logísticos. Apesar do pequeno quadro funcional, a empresa ocupa uma área de $725 \mathrm{~m}^{2}$, este utilizado para seu escritório e também para estocagem de produtos.

Para o objetivo deste estudo, onde verifica-se a história da empresa no espaço de tempo analisado, de 2006 à 2016. Durante esse foram escolhidos três períodos estratégicos devido a identificação de mudanças significativas na organização. Por meio da obtenção dos dados coletados para a pesquisa, estes períodos foram analisados de forma analítica seguindo o modelo de Pettigrew et al. (1992) identificando seu conteúdo (o quê), contexto (porquê) e processo (como). Posteriormente foram interpretados em base do modelo adaptado do processo empreendedor de Jeffrey Timmons apud Dornellas et al. (2014).

\subsection{Períodos De Mudança Estratégica}

\subsubsection{Período I - Oportunidade de empreender 2006 - 2007}

O empreendedor em busca de oportunidades, deslocou-se para trabalhar no Rio Grande do Sul como representante comercial, porém, devido a algumas adversidades acabou sendo despedido nas duas empresas em que trabalhava. Após uma nova oportunidade, prestou seu serviço de forma mais que satisfatória e a mesma empresa que havia lhe despedido, fez novamente o contato com empreendedor, lhe propondo uma oferta para se tornar distribuidor, caso, não aceita-se a proposta seria contratado outro prestador de serviços. Desse modo, o empreendedor vislumbrou uma oportunidade, e arriscou-se a abrir a empresa, se efetivando como distribuidor. Inicialmente distribuía para duas empresas, sendo uma delas a que prestava serviços como representante e a que havia feito a proposta.

Iniciou com capital muito baixo por meio de um financiamento bancário, mas, acima de tudo com coragem para as adversidades e realização do trabalho. As atividades da empresa iniciaram na própria casa do empreendedor de forma legal e integra. O quadro funcional contava com apenas dois colaboradores, o próprio empreendedor e sua esposa, que lhe auxiliou em todas atividades necessárias.

A empresa distribuía inicialmente para lojas pequenas e comercializava produtos de baixo valor. $\mathrm{O}$ próprio empresário desempenhava várias funções ao mesmo tempo, como vendedor, distribuidor, diretor financeiro, diretor logístico e todas as demais atividades que eram necessárias em conjunto com sua esposa. No início da semana realizava as vendas, para então próximo ao final de semana o mesmo realizar as entregas dos produtos. Realizava todas
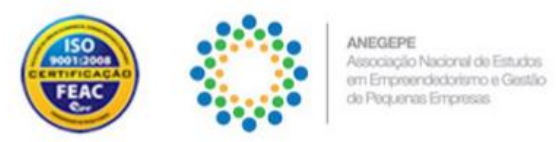

Realizadores:
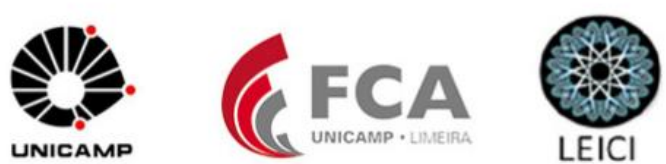
atividades em busca do crescimento e desenvolvimento da empresa sempre da forma mais correta possível, dentro da legislação vigente e com respeito aos clientes. Dedicou-se muito ao atendimento pessoal de seus clientes, percebendo assim o reconhecimento possibilitando um grande diferencial para seu negócio. O planejamento estratégico não existia formalmente, mas sim em sua mente e assim buscava o crescimento do negócio.

\subsubsection{Período II - Posicionamento e Inovação 2008 - 2014}

Conforme o decorrer dos anos a empresa cresceu e tornou-se necessário alugar um local com $60 \mathrm{~m}^{2}$. Posteriormente, com o crescimento contínuo dos negócios, em meados de 2013 foi necessário a locação de mais $60 \mathrm{~m}^{2}$, onde a empresa foi instalada, com estocagem e escritório na mesma estrutura, pois antes não havia possibilidade. Foi necessário também investir em um sistema de gestão e controle. No decorrer do ano devido a legislação ter obrigado a implantação e emissão de nota fiscal eletrônica, a empresa teve de se reestruturar e trocar seu fornecedor de tecnologia da informação. Deste modo, também foi necessário aumentar seu número de colaboradores e inicialmente foi contratada uma secretária para auxiliá-los na gestão e também aumentou para três representantes comerciais visando ampliar a região do Rio Grande do Sul. Nesse período trabalhou com produtos de laboratório e agropecuários totalizando em torno de 500 produtos no portfólio.

O empreendedor sempre buscou informações com clientes e parceiros, com isso prospectou tecnologia e um parceiro para desenvolver um novo produto, mais especificamente um sal mineral de marca própria. O objetivo do produto foi melhorar a produção de leite na vaca, atuando como suplemento para o animal, inexistindo semelhante no mercado. Desta forma houve um novo posicionamento da empresa no mercado, investindo na qualidade do produto e em 2011 foi definida uma marca e assim a empresa aprimorou seu produto com probióticos e leveduras, desta forma agregando valor ao produto mas também elevando seu preço. Devido a vários fatores tais como a qualidade e inovação do produto, o preço não se fator decisório de compra para os clientes, atendimento diferenciado realizado além dos lojistas, auxílio técnico para o produtor rural e enquanto os concorrentes da empresa focavam o preço, a empresa tomou uma atitude diferenciada e posteriormente esse produto se tornou o carro chefe chegando a representar mais de $60 \%$ das vendas.

Em meados de 2009 a empresa teve contratempos, devido à falta de conhecimento do empresário sobre a patente marca e produtos. Uma empresa concorrente havia registrado a marca do produto, exigindo a mudança da marca ou pagamento de royalties para ela, desta forma, a venda do seu produto teve de ser interrompida, com a mudança necessária do nome da marca e registro para sua proteção. Também foram desenvolvidas alianças estratégicas com fornecedores visando um melhor atendimento, e uma parceria mais forte para atender e delimitar áreas exclusivas, dificultando assim a entrada de novos concorrentes.

A terceirização logística nunca foi uma opção pois sempre contou com logística própria desde o início das atividades, para atender regiões mais afastadas e interior do estado. Neste período tinha 2 caminhões para realizar entregas e focar no crescimento da empresa.

Devido a fraude do leite ocorrida na região sul do país, o faturamento da empresa foi comprometido por mais ou menos 1 ano, e meio de certa forma freando um pouco seu
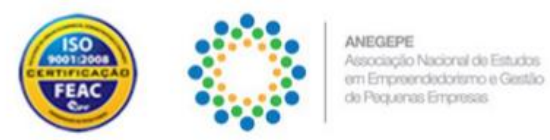

Realizadores:
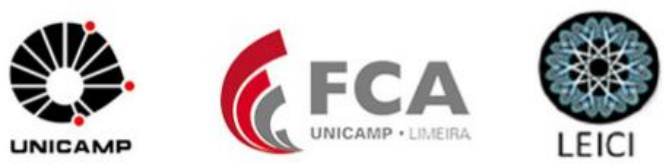
crescimento. Não houve um déficit mas sim uma estagnação que aos poucos tem sido recuperada.

\subsubsection{Período III - Expansão e Crescimento 2015 - 2016}

Desde seu início a empresa teve um aumento em seu faturamento de 25 a $30 \%$ a cada ano e desta forma precisou se reestruturar ampliando seu estabelecimento para $250 \mathrm{~m}^{2}$. No período de 2014-2015 mesmo estagnado, devido a fraude do leite, desde o início de 2016 a empresa vem apresentando bons resultados, almejando seu faturamento planejado pelo empreendedor no decorrer do ano. Conta com 500 produtos de fornecedores e mais 50 produtos de marca própria, almejando ainda este ano inovar em um novo produto para limpeza do material de ordenha.

Neste período foi investido em capacitação da sua mão de obra para um melhor atendimento técnico aos seus clientes, aumentando assim seu atendimento pessoal e focando na diferenciação do seu produto. Atualmente, a empresa possui vendas pelo site da empresa, através do contato direto com o televendas ou através do contato direto com seus representantes. Esses últimos atuam perto de sua localidade para que assim tenham uma melhor qualidade de vida e fiquem próximos da família, agindo assim também como fator motivacional. A empresa planeja metas tanto mensais quanto anuais e quando estas são atingidas todos os colaboradores são bonificados.

A logística atual da empresa é composta por 3 caminhões atendendo toda região do Rio Grande do Sul, Santa Catarina e Paraná. Tem focado no atendimento pessoal como diferencial competitivo e como ferramenta de relacionamento. Atualmente a empresa está construindo sua sede própria em uma área industrial da cidade estabelecida em uma área de $725 \mathrm{~m}^{2}$ com escritório e área para armazenagem. Almeja até 2018 fabricar seu produto de forma própria sem depender de terceiros visando redução de custos e prestar um serviço diferenciado para seus consumidores. Desta forma, a empresa terá condições de implantar uma área específica de pesquisa e desenvolvimento.

O Quadro 1 a seguir busca sintetizar os processos de estratégias e mudanças passados pela organização.

Quadro 1: Períodos De Mudança

\begin{tabular}{|l|l|lr|lr|}
\hline Período & I-Abertura precoce & $\begin{array}{l}\text { II - Desafios de } \\
\text { mercado }\end{array}$ & $\begin{array}{l}\text { III - Empresa } \\
\text { Planejada }\end{array}$ \\
\hline Ano & $2006-2007$ & & $2008-2014$ & $2015-2016$ & e \\
\hline Mudança & $\begin{array}{l}\text { Oportunidade de } \\
\text { empreender }\end{array}$ & $\begin{array}{l}\text { Posicionamento } \\
\text { Inovação }\end{array}$ & $\begin{array}{l}\text { Expansão } \\
\text { Crescimento }\end{array}$ \\
\hline
\end{tabular}

Fonte: Elaborado pelos autores, 2016. 


\subsection{Análise Teórica dos Períodos}

\subsubsection{Período I - Oportunidade de empreender 2006 - 2007}

O primeiro período tem como fator principal a decisão de abertura da empresa, e as instabilidades do mercado que afetaram o empreendedor. Mintzberg et al. (2009) explica que dentre todas características que afetam a personalidade do empreendedor, existe em si fortes necessidades da independência e da realização pessoal, relacionado a sua tomada de decisão para aceitar riscos e sua autoridade. Também apresentado pelo autor que a estratégia do líder empreendedor existe de forma consciente, enfatizado pelas experiências passadas e sua intuição, mas atuando como perspectiva de direção, e principalmente de longo prazo para a organização. No caso apresentado o crescimento já estava cognitivamente tomando seu rumo.

Deste modo, o primeiro período estratégico da organização teve como influencia forte o determinismo ambiental, segundo Hrebiniak e Joyce (1985) é caracterizado quando uma empresa é fortemente influenciada pelo meio, incentivando e forçando assim, de certo modo, a abertura da empresa. Mesmo a influência do ambiente como determinante nesse período, para Dornellas et al. (2014) a criatividade do empreendedor em conjunto com os fatores ambientais do mercado, podem resultar em uma criação de empresa, mesmo que, não seja forte o suficiente para alterar o ambiente, pois são fortemente influenciadas pelo meio. Assim foi chave a autossuficiência inicial.

Desta forma o primeiro período marca-se pela oportunidade vislumbrada e pela grande incerteza do ambiente. Da forma que o determinismo ambiental agiu para incentivar a abertura da empresa, a grande incerteza e riscos, as ameaças na entrada acabam retirando uma fatia do mercado podendo ocasionar uma redução de custos e diminuir a lucratividade do setor (KOTLER, 2004; WRIGHT et al., 2010). Os autores ainda inferem que estes fatores, podem resultar em uma retaliação dos concorrentes que já existem no mercado.

A análise do período foi realizada através do modelo adaptado do processo empreendedor de Jeffrey Timmons. Dado que, o empreendedor vislumbrou uma ótima oportunidade para si, em abrir o negócio. Pela sabedoria que o empreendedor detinha sobre a demanda e da necessidade que havia no mercado. Desta forma, baseou-se puramente em sua capacidade cognitiva, transformando em uma oportunidade. Mesmo com seus recursos limitados, quase escassos, e sua equipe composta inicialmente por duas pessoas houve uma dedicação e empenho crucial para o início do negócio. Assim, a oportunidade do negócio predominava devido a necessidade que existia no mercado e o empreendedor vislumbrou seu crescimento em base dessa variável, com seus recursos escassos e seu baixo quadro funcional, o modelo é composto como base, a alta predominância da incerteza ambiental.

\subsubsection{Período II - Posicionamento e Inovação 2008 - 2014}

A reestruturação organizacional ocorreu no período II, devido as contratações de mão de obra, bem como a necessidade de expansão da empresa propiciou inicialmente uma estratégia competitiva de crescimento interno. Segundo Wright et al. (2010) isto ocorre, por meio do aumento das vendas e da força de trabalho, preservando a cultura da organização,
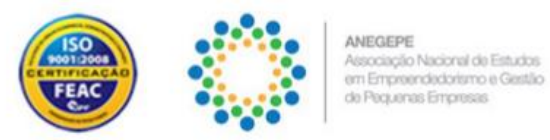

Realizadores:
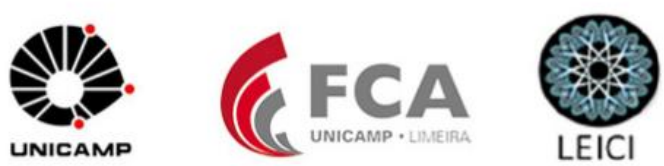
eficiência do trabalho. Assumir o compromisso de crescer por meio da inovação interna e disponibilizar recursos para este objetivo (AAKER, 2009)

Para Dornellas et al. (2014) a oportunidade vislumbrada, ocorre devido ao processo de mudança empreendedora que acontece nas organizações, por meio da antecipação de mudanças. Um empreendedor criativo consegue vislumbrar possíveis mudanças, inovando enquanto outros ainda estão no processo de concepção. Ainda segundo os autores a experiência do empreendedor age como fator chave para reconhecer e antecipar oportunidades de mercado, caracterizado como marco do empreendedor. O desenvolvimento e aprimoramento de produtos, o foco na qualidade do atendimento pessoal e técnico, contribuíram para seu crescimento. Como citado por Tigre (2006), a empresa realizou uma coleta articulada para inovar, ou seja, através de fontes internas e externas. Corrobora com a afirmação Wright et al (2010), pois melhora os resultados da organização através da inovação de produtos, diferenciação dos produtos e satisfaz os clientes.

Através dessa inovação a empresa teve um posicionamento diferenciado, segundo Porter (2004) com estratégia de diferenciação permitindo conseguir retornos acima da média, se tornando assim mais forte e competitiva contra seus concorrentes, proporcionando uma lealdade maior com a organização e também menos sensitiva ao preço devido ao oferecimento de um melhor desempenho e qualidade.

Para Kotler (1997) os profissionais da empresa são consultores e tem como objetivo ajudar os clientes, na administração dos negócios que dirigem. Kotler (2001) infere que os relacionamentos entre empresas e clientes precisam buscar a criação de valor. Isso corrobora com os objetivos da empresa visando a competitividade no mercado.

Também neste período marcou-se a retaliação de empresa concorrente, devido ao processo de aproveitamento dos concorrentes sobre a não proteção da marca. Segundo Wright et al. (2010) a entrada em determinados setores do mercado pode ser difícil, devido a retaliação existente nos concorrentes devido aos ativos não podendo ser transferidos para outros nichos de mercado, sendo assim afetando diretamente as empresas já atuantes.

Deste modo, no modelo adaptado do processo empreendedor de Timmons, partindo da oportunidade nesse período, foi caracterizado pela identificação da inexistência de um produto, reposicionando como marca e inovando seus produtos. A empresa já detinha de recursos para coletar maiores informações com seus parceiros, em busca do seu desenvolvimento e aprimorar seu planejamento. Também teve de ampliar seu quadro funcional para suprir a demanda e acompanhar sua evolução. Assim este período é caracterizado pelo aumento dos recursos organizacionais, ou seja, a empresa estava atuando estrategicamente no ambiente, ou seja, agindo com voluntarismo contra o ambiente. A base do modelo está inclinada para a direita, devido a força que a organização criou no ambiente.

\subsubsection{Período III - Expansão e crescimento}

Nesse período a empresa tem a oportunidade de expansão e crescimento dos negócios devido ao mercado em ascensão. A ampliação da área física por meio da construção de sede própria e o investimento em capacitação dos funcionários demonstram a visão do empreendedor em estar preparado para aproveitar as oportunidades propiciadas pelo mercado. Com isso, a
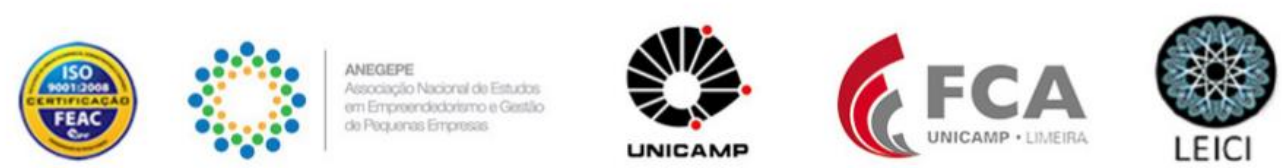
empresa busca atingir um novo patamar adotando uma nova estratégia que Porter (1986) denomina como enfoque em custo.

Essa estratégia faz parte das conhecidas estratégias genéricas de Porter (1986): liderança em custo, diferenciação e foco. $\mathrm{O}$ modelo é realizado em enfoque em custo e enfoque na diferenciação. $\mathrm{O}$ enfoque em custo consiste no custo mais baixo possível. Essa estratégia busca como vantagem competitiva a empresa ter um custo menor que os concorrentes e assim funcionar como um mecanismo de defesa contra a rivalidade das empresas concorrentes.

Ao que tange a custos, a empresa tem a possibilidade de se manter competitiva tanto em momentos bons quanto em momentos de crise. Bruni e Fama (2000) discorrem que os custos são os dispêndios utilizados na produção de bens ou serviços, principalmente com matériaprima, colaboradores, onde também reduzindo os custos a organização consegue se manter mais lucrativa (AAKER, 2009)

Os mesmos precisam ser gerenciados com muito cuidado, visto que um aumento devido a uma necessidade de momento pode impactar significativamente no caso de uma variação das receitas. De qualquer forma os mesmos existem, pois, são sacrifícios necessários com os quais as organizações precisam arcar a fim de atingir os objetivos organizacionais (BRUNI; FAMA, 2000).

Considerando esse período como expansão e crescimento do processo empreendedor com base no modelo de Timmons tem-se um momento em que a estratégia é preponderante ao quesito incerteza. Então, ocorre que a empresa vem buscando a diferenciação do produto com o objetivo de internalizar esse processo produtivo na fábrica própria, bem como, o desenvolvimento de novos produtos. Com isso, a empresa pretende conseguir se manter competitiva perante os concorrentes devido a internacionalização do processo de desenvolvimento e produtivo, com uma análise e controle de custos, vislumbrando assim a dominar o mercado com o gerenciamento de custos. Desta forma, a base do processo é inclinado para a direita, em base do processo estratégico criado pela organização.

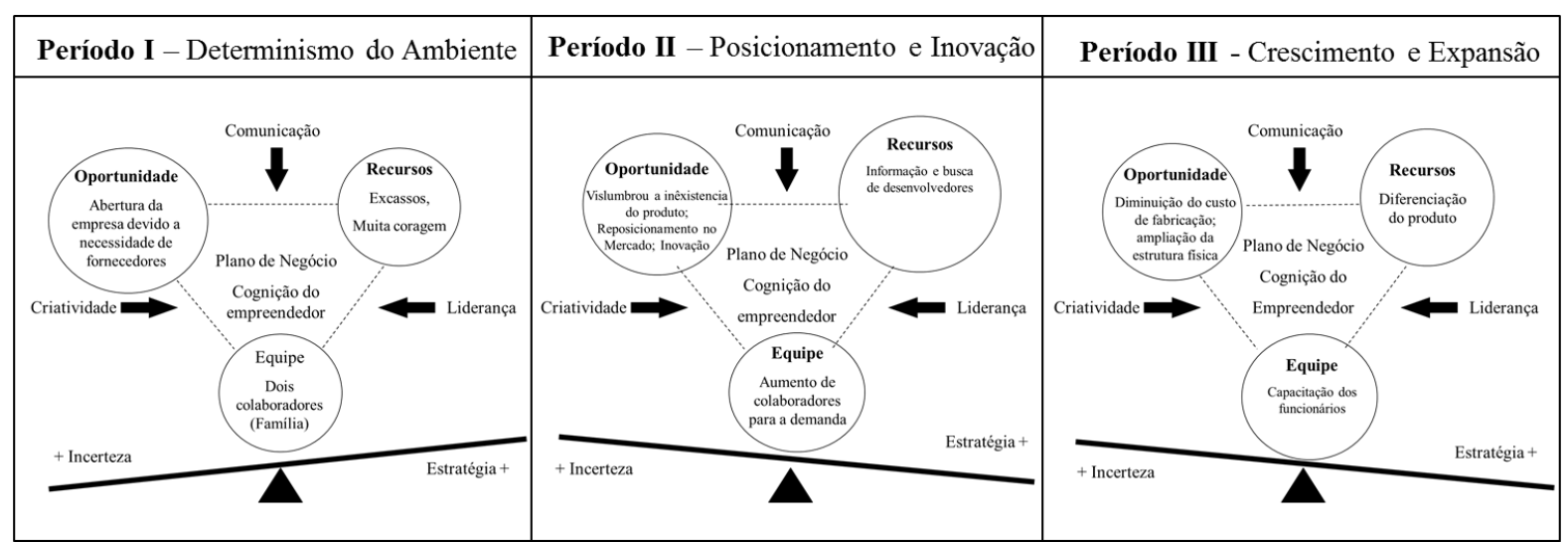

Figura 3. Analise dos Períodos Estratégicos através do Processo Empreendedor.

Fonte: Dados da pesquisa, 2016. 


\section{Considerações finais}

O acontecimento de mudanças mostra-se presentes em todos os nichos de mercado, fazendo com que as organizações estejam sempre em um processo contínuo de mudança e adaptação para que assim se mantenham no cenário competitivo. Desta forma a pesquisa teve como objetivo analisar o processo de mudança, a partir da análise do contexto, conteúdo e processo de Pettigrew et al. (1987) sendo este analisado através do modelo adaptado do processo empreendedor de Jeffrey Timmons (Figura 2), visando a oportunidade, recursos equipe e possuindo como base a incerteza e a estratégia.

Através da coleta e análise pode-se identificar três períodos, caracterizados de mudança e adaptação estratégico na história da organização. O empreendedor iniciou suas atividades em 2006 e mantém suas atividades com muito esforço e dedicação, como prerrogativas iniciais. O primeiro período foi identificado com nomenclatura de oportunidade de empreender, onde a abertura da empresa se concretizou devido as forças do ambiente influenciando para iniciar as atividades. Este foi composto por uma oportunidade como grande fator no processo empreendedor, com recursos escassos, equipe limitada, porém mesmo com estas características com autossuficiência.

O período dois se caracteriza pelos investimentos e aprimoramentos realizados pela organização, em inovação e aprimoramento de produtos, alocando recursos para um posicionamento diferenciado. Este período teve como prioridade o foco na qualidade dos produtos, com o quadro funcional em desenvolvimento e a formulação da estratégia criada pelo líder empreendedor.

Por fim o último período estratégico e formalizado pela expansão da organização visando assim manter sua diferenciação de produto, mas focando também em sua produção própria, se posicionando através dos custos. A empresa apresenta uma boa capacidade financeira e de recursos próprios em crescimento, maiores investimentos tanto em sua mão de obra quanto a qualificação da mesma. Percebe-se assim que a empresa está atuando de forma muito mais voluntária sobre o ambiente.

Confirmando assim o processo de evolução do empreendedor citado por Mintzberg et al. (2010) apresenta o processo de formulação da estratégia à medida que este se desdobra. Sua essência está na formulação da estratégia com foco exclusivo no líder baseada na visão, isto é, uma obra do líder. No desenvolver dos anos o processo estratégico foi surgindo inteiramente cognitivamente. Deste modo, o resultado da pesquisa além de apresentar inferências teóricas, é realizada a adaptação do modelo de Timmons para o processo empreendedor tendo como base a estratégia, sendo considerado o determinismo e o voluntarismo da organização. Na pesquisa foi apresentando o modelo de Timmons, que até então não havia sido adaptado e nem interpretado por esta lente estratégica.

Desta forma, as decisões estratégicas nos permitem inferir que o desenvolvimento e crescimento da organização fluiu de forma contínua nos períodos, podendo assim dizer que as mudanças desenvolvidas agiram de forma influente para sua permanência no mercado competitivo. O presente estudo por ser do caso específico da empresa Sivet, não busca a generalização das inferências encontradas na pesquisa. Porém, recomenda-se estudos que contemplem e avaliem o processo de mudança realizado em outros contextos em busca dos aprimoramentos tantos de estudos empíricos quanto teóricos.
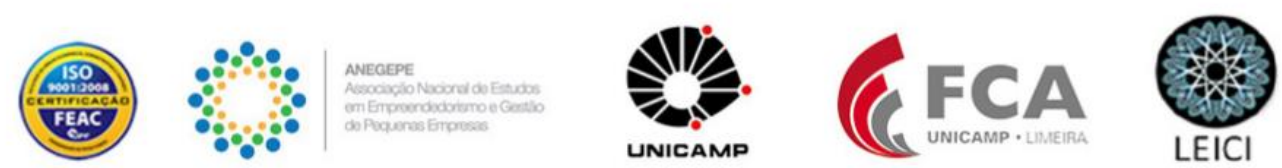
Sugere-se um aprimoramento do modelo Timmons por outros pesquisadores, podendo identificar possíveis variáveis que venham a influenciar esse processo de empreender, como no modelo, a união do processo de mudança de Pettigrew et al. (1987) em conjunto com o modelo de Timmons. A interdisciplinariedade entre as lentes teóricas, podem contribuir para evolução do tema, resultando uma maior influência do meio acadêmico, temas relacionados ao processo e mudança estratégica, processo empreendedor e também a influência do líder organizacional.

\section{REFERENCIAS}

AAKER, David A. Administração Estratégica de Mercado 9ed. Bookman Editora, 2009.

BRUNI, A. L.; FAMA, R. Gestão de custos e formação de preços: com aplicações na calculadora HP 12C e Excel. Editora Atlas SA, 2000.

CERETTA, S.; SAUSEN, J. O. Mudança e adaptação organizacional: um estudo do reposicionamento estratégico com vistas à autos sustentação financeira de uma escola de formação profissional. In: ENCONTRO DA ANPAD, 34, 2010, Rio de Janeiro. Anais... Rio de Janeiro: Anpad, 2010.

DORNELAS, J. C. A.; TIMMONS, J. A.; SPINELLI, S. Criação de novos negócios: empreendedorismo para o século 21. 2010.

DRUCKER, P. Administrando em tempos de grandes mudanças: tradução Nivaldo Montingelle Jr.; supervisão técnica Liliana Guazzelli. São Paulo: Pioneira, 1995.

HAMEL, G.; PRAHALAD, C. K. Competindo pelo futuro. Rio de janeiro: Campus, v. 301, 1995.

IBGE - INSTITUTO BRASILEIRO DE GEOGRAFIA E ESTATÍSTICA. Indicadores IBGE - Estatística da Produção Pecuária - Março de 2016 Disponível em: < http://www.ibge.gov.br/home/estatistica/indicadores/agropecuaria/producaoagropecuaria/abat e-leite-couro-ovos_201504_publ_completa.pdf> Acesso em: 15 Julho. 2016.

LAZZARETTI, K; VARGAS, S. M. L.; ROSSETTO, C. R. Processo de Adaptação Estratégica: Aplicação do Modelo de Hrebiniak e Joyce em uma Instituição de Educação Profissional. XXXII Encontro Nacional De Engenharia De Produção, out. 2012.

MINTZBERG, H. An emerging strategy of "direct research". In: Van Maanen, J. (Ed.) Qualitative Methodology. London: Sage, 1979.

MINTZBERG, H. Patterns in strategy formation. Management Science, v. 24, n. 9, p. 934948, 1978.

MINTZBERG, H.; AHLSTRAND, B.; LAMPEL, J. Safári da estratégia. Bookman Editora, 2009.
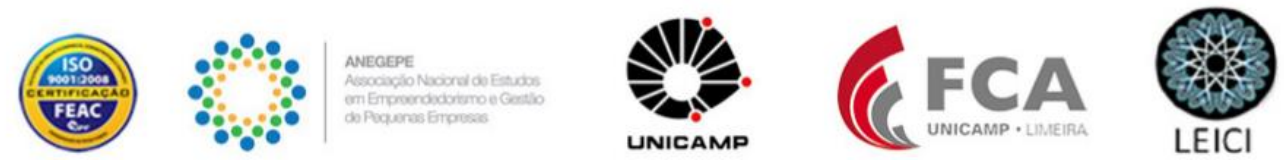
PETTIGREW, A. Context and action in the transformation of the firm. Journal of Management Studies, Oxford, v. 24, n. 6, p. 649-670, 1987.

PETTIGREW, A.M.; FERLIE, E.; MCKEE, L. Shaping strategic change. London: Sage, p. $1-30,1992$.

PORTER, M. E. Estratégia competitiva: técnicas para análise de indústrias e da concorrência. Campus, 1986.

PORTER, M. Estratégia competitiva. Elsevier Brasil, 2004.

ROSSETTO, C. R. Adaptação estratégica organizacional: um estudo multi-caso na indústria da construção civil - setor de edificações. 1998. 194 fl. Tese (Doutorado em Engenharia de Produção) - Universidade Federal de Santa Catarina. 1998.

TIGRE, P. Gestão da inovação: a economia da tecnologia no Brasil. Elsevier Brasil, 2006.

WRIGHT, P.; KROLL, M. J.; PARNELL, J. Administração estratégica: conceitos. São Paulo: Atlas, 2000.

YIN, R. K. Estudo de Caso - Planejamento e Método. 2. ed. São Paulo: Bookman, 2001.

STEVENSON, Howard H. A new paradigm for entrepreneurial management. Division of Research, Harvard Business School, 1984. 